\section{Uncommon cause of late onset anasarca after cardiac surgery}

A 10-year-old girl presented with a history of having loose stools and generalised swelling for a 1-month period. She had complex congenital cyanotic heart disease-double outlet right ventricle with anatomy unsuitable for two-ventricle repair. She had undergone Fontan surgery 3 years previously. Fontan completion was staged after pulmonary artery (PA) banding and bidirectional Glenn surgery. Her laboratory parameters showed hypoproteinemia with hypocalcaemia (serum protein $3.4 \mathrm{gm} / \mathrm{dL}$, serum albumin $1.3 \mathrm{gm} / \mathrm{dL}$, serum calcium $5.6 \mathrm{mg} / \mathrm{dL}$ ). The patient's clinical condition was highly suggestive of a particular syndrome and she was started on treatment for that condition. Her echocardiogram showed significant haemodynamic findings (figure 1). She was referred for cardiac catheterisation and a percutaneous intervention was performed (figure 2A, B). Following the intervention, she improved dramatically with subsidence of symptoms and signs within 3 days.

\section{QUESTION}

What is the significant unexpected haemodynamic finding identified in this patient's echocardiographic image (figure 1)?

1. Ventricular septal defect (VSD) shunt

2. Atrial septal defect (ASD) shunt

3. Antegrade flow in the right ventricular outflow tract (RVOT)

4. Left ventricular outflow tract obstruction (LVOTO)

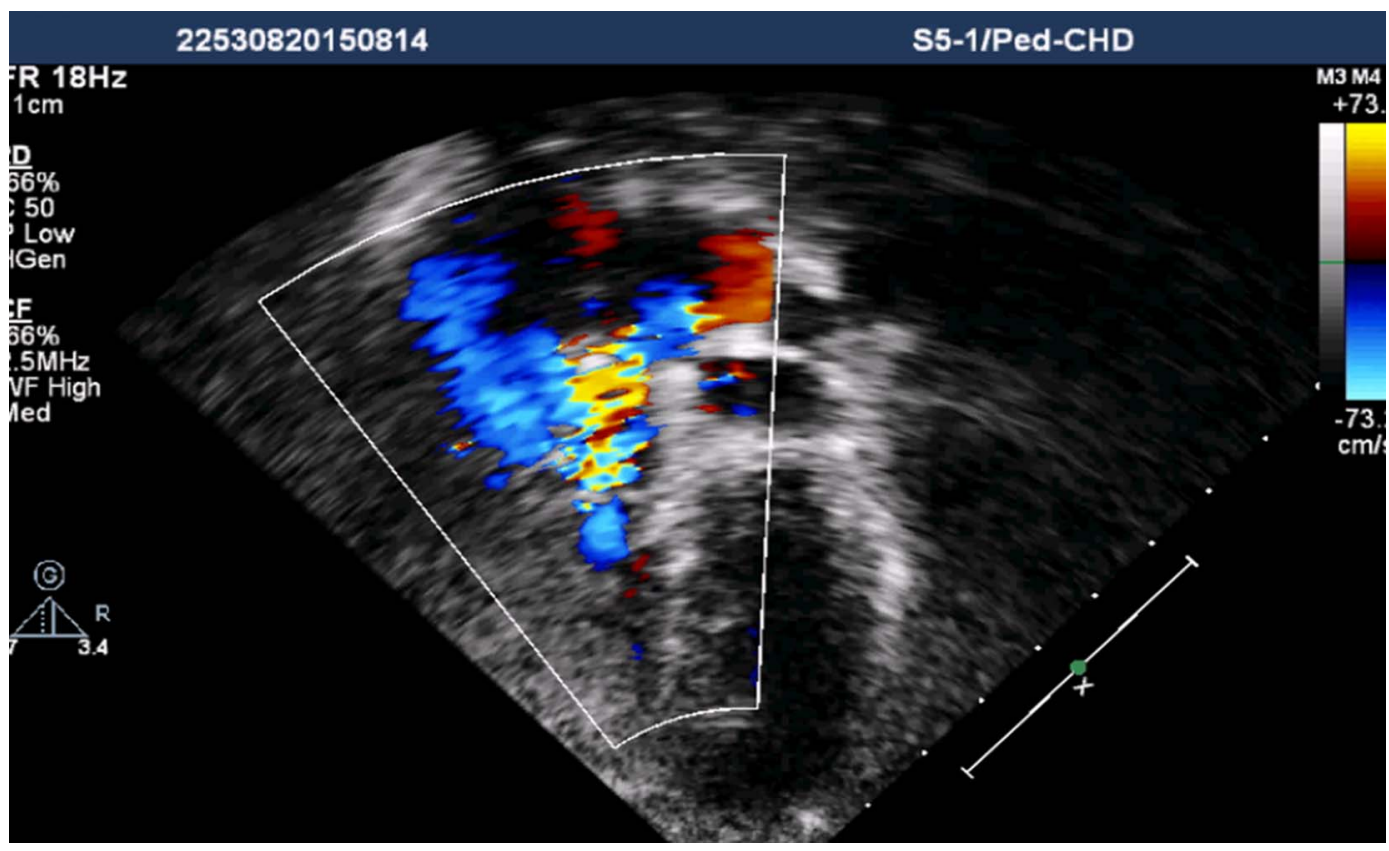

Figure 1 Color Doppler echocardiography image with anterior tilt.
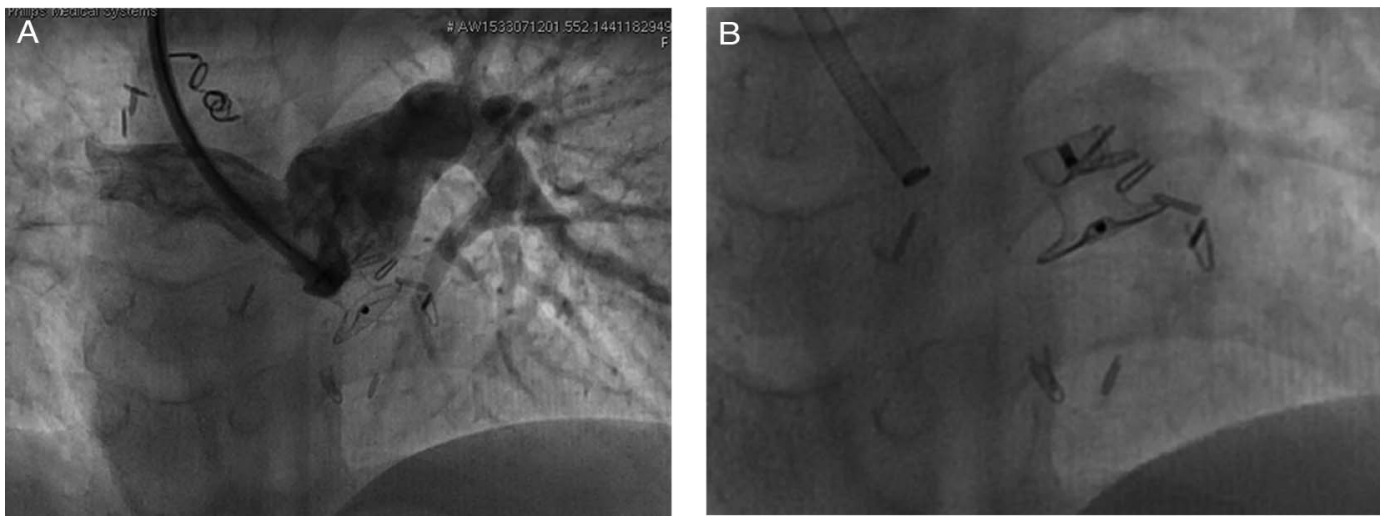

Figure 2 (A, B) Fluoroscopy images with cranial $30^{\circ}$ view. 
Figure 3 Algorithm protocol for management of patients with protein losing enteropathy. GI, gastrointestinal.

\section{Cardiac Cath to Assess Hemodynamics + Upper and Lower GI Endoscopy with Biopsy}

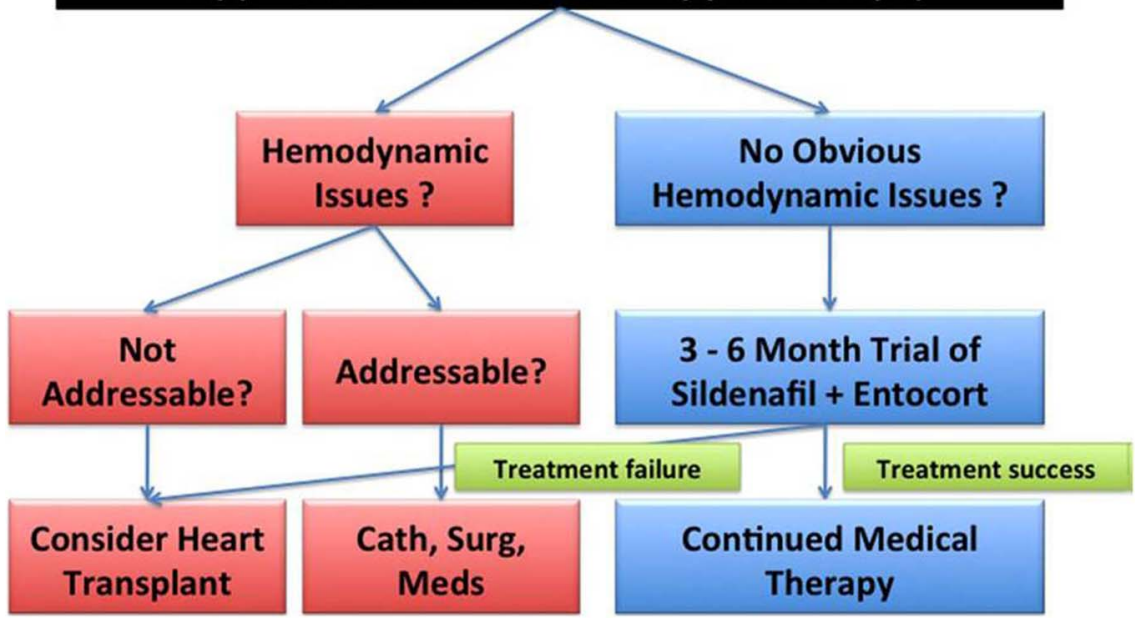

\section{ANSWER}

This girl is suffering from protein losing enteropathy (PLE) due to a failing Fontan circuit.

This four chamber echocardiographic view with anterior tilt shows antegrade flow through the PA which had previously been banded. Such flow is detrimental in Fontan physiology and can have serious haemodynamic consequences. ${ }^{12}$ Antegrade flow may increase PA pressures and lead to increased resistance in the Fontan circulation, which in turn may increase resistance in the mesenteric circulation. This may contribute to the development of PLE. On cardiac catheterisation the patient had a high mean PA pressure $(17 \mathrm{~mm} \mathrm{Hg})$. Therefore, option 3 is the correct answer.

The patient underwent device (Amplatzer duct occluder) closure of the RVOT through a Glenn shunt (figure 2A, B). Understanding the pathophysiology may be useful in the management of PLE in Fontan physiology (figure 3 ). ${ }^{3}$

A large VSD is part of the primary condition, and the ASD, if flowing right to left, may simply reflect the elevated pressure in the system (so options 1 and 2 are not correct). There is no left ventricular outflow obstruction (so option 4 is not correct).

\section{Chintan Bhatt, ${ }^{1}$ S Radhakrishnan, ${ }^{2}$ Anupama Nair ${ }^{2}$}

${ }^{1}$ Fortis Escorts Heart Institute, New Delhi, India

${ }^{2}$ Department of Pediatric Cardiology, Fortis Escorts Heart Institute, New Delhi, India

Correspondence to Dr Chintan Bhatt, Fortis Escorts Heart Institute, Okhla Road, New Delhi 110025, India; chintan18bhatt@yahoo.co.in
Contributors CB prepared the manuscript, AN helped in reviewing the manuscript, and SR re-reviewed the manuscript and helped in preparing the final draft.

Competing interests None declared.

Provenance and peer review Not commissioned; internally peer reviewed.

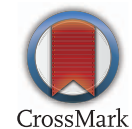

To cite Bhatt C, Radhakrishnan S, Nair A. Heart Asia 2016;8:40-41. doi:10.1136/ heartasia-2015-010697

Heart Asia 2016:8:40-41. doi:10.1136/heartasia-2015-010697

\section{REFERENCES}

1 Rychik J, Goldberg D, Rand E, et al. End-organ consequences of the Fontan operation: liver fibrosis, protein-losing enteropathy and plastic bronchitis. Cardiol Young 2013;23:831-40.

2 Tanamati C, Guimarães VA, Penha JG, et al. Fontan postoperative complication: antegrade pulmonary flow. Rev Bras Cir Cardiovasc 2011;26:137-9.

3 Rychik J. Protein-losing enteropathy after Fontan operation. Congenit Heart Dis 2007;2:288-300. 